\title{
STUDY OF THE INTERFERENCE EFFECT OF SURROUNDING BUILDINGS ON WIND FLOW IN URBAN STREET CANYONS WITH KAPPA EPSILON TURBULENCE MODEL
}

\author{
Fernanda C. Cezana ${ }^{1,}$, Elisa V. Goulart ${ }^{1}$, Jamily F. Stocco ${ }^{2}$, Artur Burgo ${ }^{2}$, Lizandra B. \\ Föeger $^{2}$, Reginaldo R.C. de Paula ${ }^{3}$, Bianca H. Souza ${ }^{3}$ \\ ${ }^{1}$ Environmental Engineering Department, Ufes, Vitoria, ES, Brazil \\ ${ }^{2}$ Sanitary and Environmental Engineering Department, Ifes, Vitoria, ES, Brazil \\ ${ }^{3}$ Mechanic Technical Department, Ifes, Vitoria, ES, Brazil \\ *fe.cezana@gmail.com
}

\begin{abstract}
Numerical simulation of flow field over an idealized urban area was calculated using standard $\kappa-\varepsilon$ turbulence model to investigate the effects of surrounding buildings. The urban area was represented by six cubical scale model buildings which were arranged in a symmetric configuration and different buildings spacing, $H / W=0.5,1.0$ and 2.0. The external flow was parallel to the buildings.
\end{abstract}

\section{RESUMO}

Neste trabalho, simulações numéricas foram realizadas para investigar os efeitos de um grupo de obstáculos no escoamento do vento. Considerou-se uma região urbana idealizada formada por seis obstáculos cúbicos dispostos de forma simétrica em relação à rua com diferentes espaçamentos entre si. As interações do campo de vento com os obstáculos foram analisadas utilizando o modelo de turbulência $\kappa-\varepsilon$ padrão.

\section{INTRODUCTION}

The flow field in urban areas is largely determined by meteorological and geometric parameters, such as ambient wind velocity and building configurations. In recent years, numerical simulation studies have contributed to our understanding of the influences of meteorological parameters and building configurations on flow over an urban canyon (YASSIN, 2011). Various types of turbulence models have been employed to simulate flow 
field. The standard $\kappa-\varepsilon$ turbulence model has been commonly used in this case, despite of your deficiencies to the simulation of flow impingement and the flow separation. In this work a three-dimensional, steady, $\kappa-\varepsilon$ turbulence model was used to investigate the flow regimes over an idealized urban street canyon.

\section{NUMERICAL SIMULATIONS}

A commercial CFD code (ANSYS CFX 13.0) was used to calculate the flow field around building. The code solves three-dimensional Reynolds-average Navier-Stokes (RANS) equation using a UPWIND scheme. The governing equations for the atmospheric flow in the neutral conditions of an incompressible fluid with constant viscosity, $\mu$, based on the Reynolds-averaged Navier-Stokes approach are:

$$
\begin{aligned}
& \frac{\partial \bar{u}_{i}}{\partial x_{i}}=0 \\
& \frac{\partial\left(\bar{u}_{i} \bar{u}_{j}\right)}{\partial x_{i}}+\frac{\partial\left(\overline{u_{i}^{\prime} u_{j}^{\prime}}\right)}{\partial x_{i}}=\frac{\partial}{\partial x_{i}}\left[-\left(\frac{\bar{p}}{\rho}+\frac{2}{3} \frac{\mu}{\rho} \frac{\partial \bar{u}_{k}}{\partial x_{k}}\right) \delta_{i j}+\frac{\mu}{\rho}\left(\frac{\partial \bar{u}_{i}}{\partial x_{j}}+\frac{\partial \bar{u}_{j}}{\partial x_{i}}\right)\right]
\end{aligned}
$$

where $u_{i}^{\prime}$ and $\bar{u}_{i}$ are the fluctuating and mean velocities in the $x_{i}$-direction $(i=1,2,3) ; \bar{p}$ is the dynamic pressure and $\rho$ is the density of the fluid. The kinematic Reynolds stress $\overline{u_{i}^{*} u_{j}^{*}}$ represent the turbulent fluxes of momentum.

\section{RESULTS}

Figures 1 and 2 show the velocity vector of the flow fields on the vertical $x-z$ plane $(y / H=$ 1.0) and horizontal on the $x-y$ plane $(z / H=0.5)$ corresponding to $H / W=2.0$. Between buildings the flow was downward, see Fig. 1. So by mass conservation, the flow is redirected horizontally to the main street canyon, as a see Fig. 2. Due to the smaller space between buildings the wakes were disturbed, resulting in a skimming flow as described by Oke (1988). 


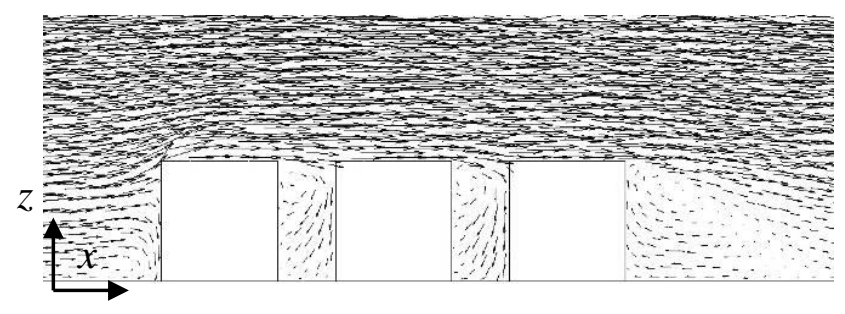

Figure 1. Velocity vector of flow field on the $x-z$ plane of the street canyon at $H / W=2.0$.

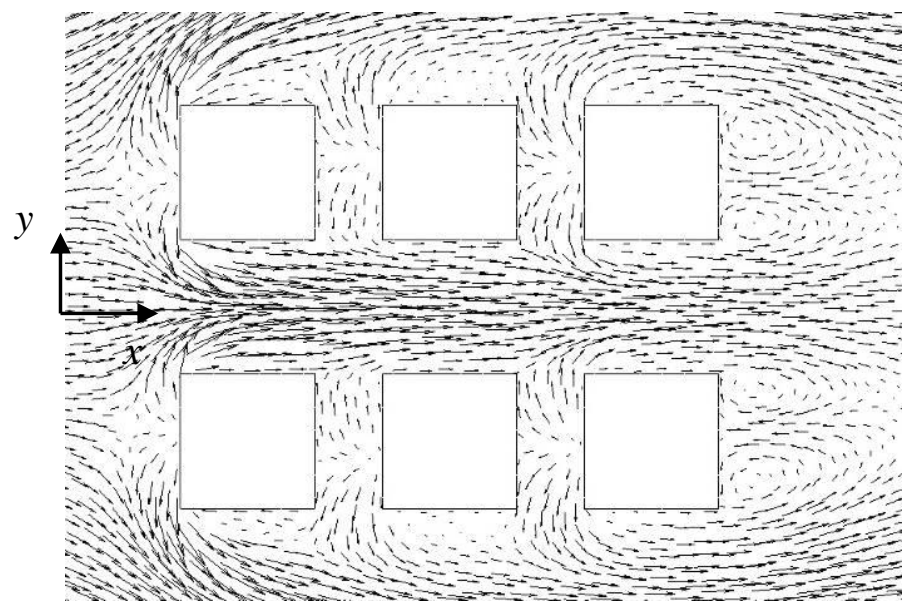

Figure 2. Velocity vector of flow field on the $x-y$ plane of the street canyon at $H / W=2.0$.

Figures 3 and 4 show the velocity vector of the flow fields on the vertical $x-z$ plane $(y / H=$ 1.0) and on the horizontal $x-y$ plane $(z / H=0.5)$ for aspect ratio $H / W=1.0$. The result showed that flow within canyon space was decoupled from flow above top of buildings, which also was characterized as a skimming flow. Analyzing the gap between buildings, it is possible to see that near the upwind building flow was downward and near the downwind building flow was upward. Horizontally, the flow was outward.

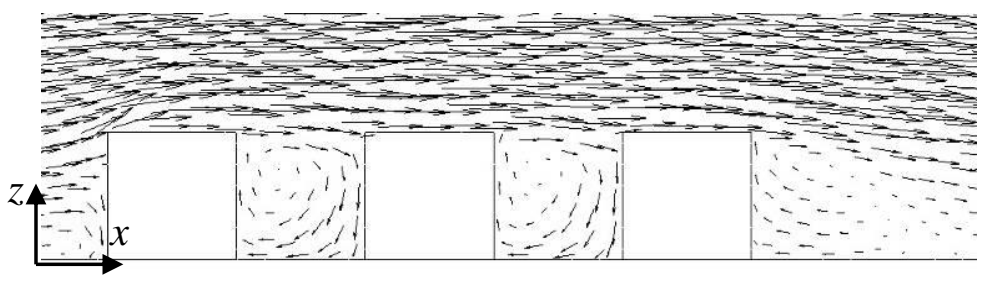

Figure 3. Velocity vector of flow field on the $x-z$ plane of the street canyon at $H / W=1.0$. 


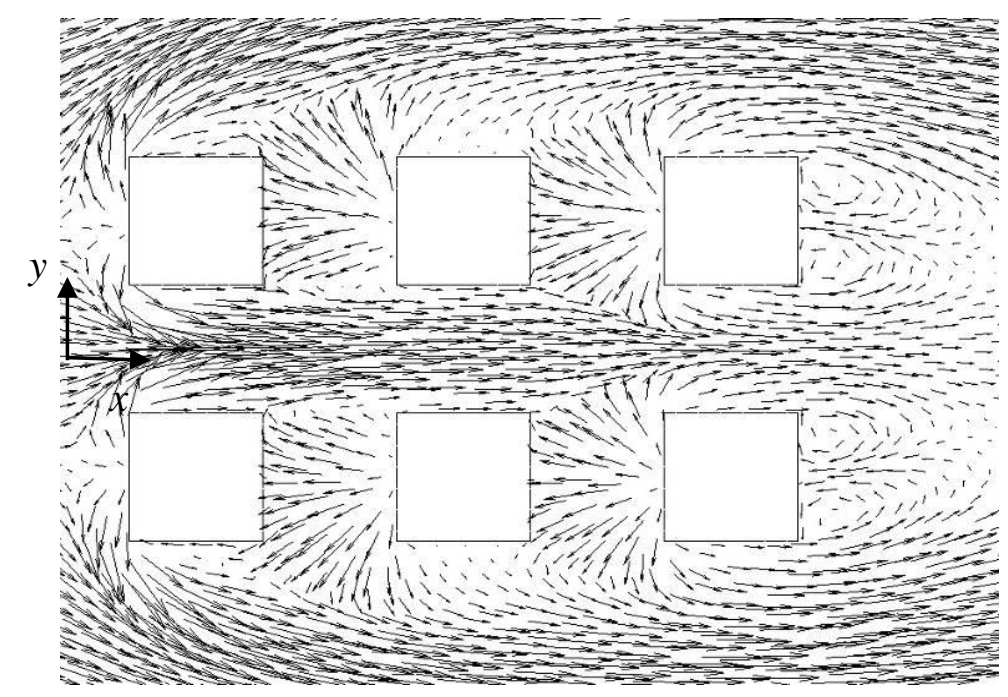

Figure 4. Velocity vector of flow field on the $x-y$ plane of the street canyon at $H / W=1.0$.

Figures 5 and 6 show the velocity vector of the flow fields on the vertical $x-z$ plane $(y / H=$ 1.0) and horizontal on the $x-y$ plane $(z / H=0.5)$ at $H / W=0.5$. Analyzing the gap between buildings, near the upwind building flow was downward and near the downwind building flow was upward, see Fig. 5. The numerical results presented the influence of street intersection on the flow field, which was observed the formation of two recirculation zones in the near wake behind buildings. This flow regime was characterized by transition between wake interference to isolated roughness flow.

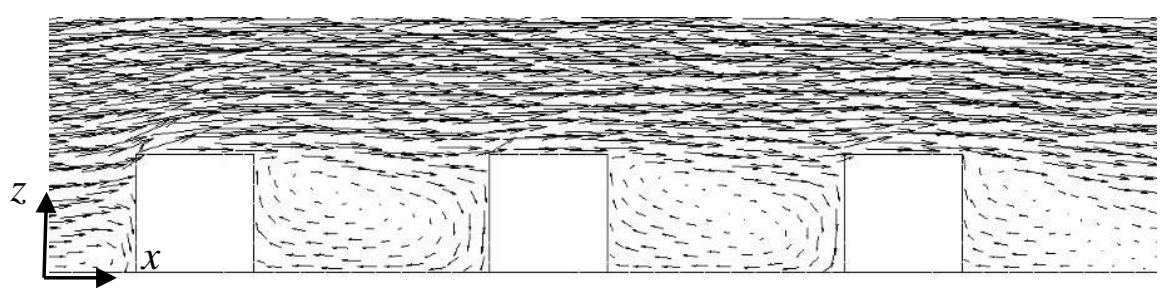

Figure 5. Velocity vector of flow field on the $x-z$ plane of the street canyon at $H / W=0.5$. 


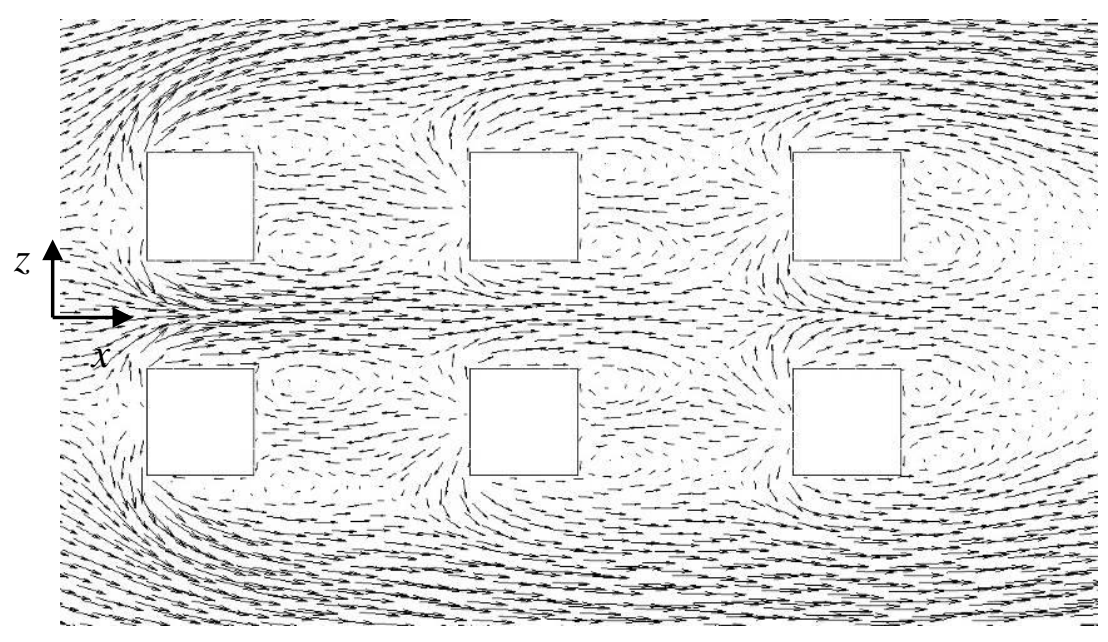

Figure 6. Velocity vector of flow field on the $x-y$ plane of the street canyon at $H$ / $W=0.5$.

Figure 7 shows the streamlines of mean velocity in the $y-z$ plane within the canyon spacing between the first and second buildings corresponding to $H / W=2.0 ; 1.0$ and 0.5 , at $x / H=4.5$. In two first cases was observed two symmetric vortices behind buildings upwind.

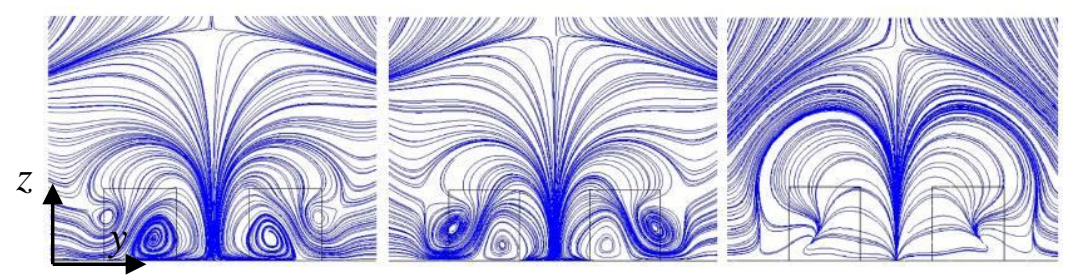

Figure $7-$ Streamlines of mean velocity on the $y-z$ plane at $H / W=2.0 ; 1.0$ and 0.5 .

Figures 8, 9 and 10 show streamline on the $x-z$ plane at $H / W=2.0 ; 1.0$ and 0.5 , respectively. Air flow upstream the first building display the standing vortex (frontal vortex) caused by boundary layer separation. At $H / W=2.0$, near top edge behind upwind building was observed the shedding vortex formation. As the canyon space increases, single large rotating vortex appear.

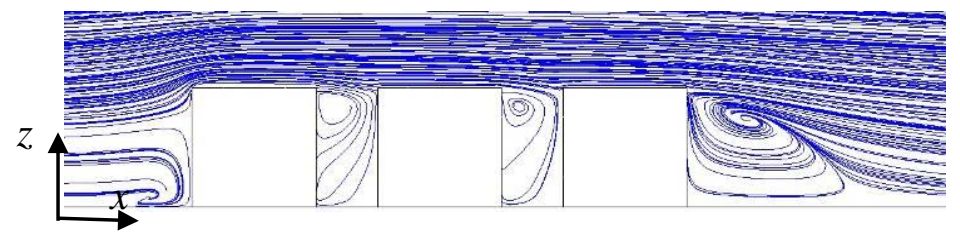

Figure 8-Streamlines of mean velocity on the $x-z$ plane at $H / W=2.0$. 


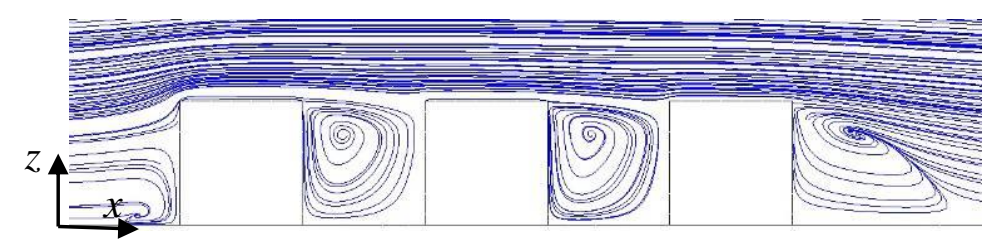

Figure 9 - Streamlines of mean velocity on the $x-z$ plane at $H / W=1.0$.

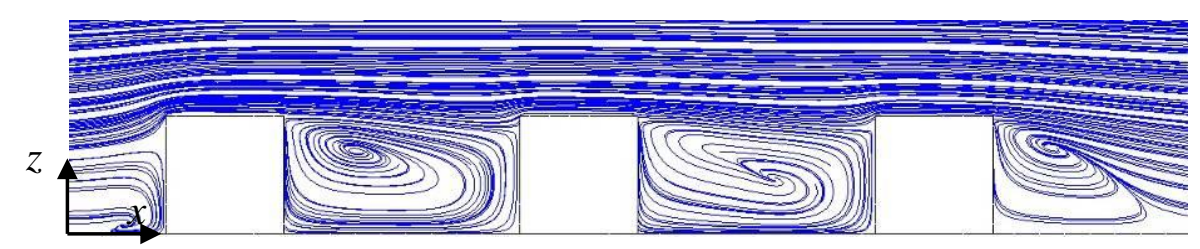

Figure 10 - Streamlines of mean velocity on the $x-z$ plane at $H / W=0.5$.

\section{CONCLUSIONS}

In this work by varying the canyon spacing it was possible to investigate numerically the skimming flow and the transition of skimming flow to wake interference flow when low cubic buildings were used.

\section{ACKNOWLEDGEMENTS}

The authors would like to acknowledge the financial support from National Council for Scientific and Technological Development (CNPq) and Vale Company, Brazil.

\section{REFERENCES}

YASSIN, M.F., Impact of height and shape of building roof on air quality in urban street canyons. Atmospheric Environment, Vol. 45, pp. 5220-5229, 2011.

OKE, T.R., Street design and urban canopy layer climate. Energy and Buildings, Vol. 11, pp. 103-113, 1988. 